\title{
O LeITOR de diáRios E A RECEPÇÃo CRÍticA de $O$ AMANUENSE BELMIRO
}

Ananda Nehmy de Almeida ${ }^{1}$

\section{RESUMO}

O objetivo deste artigo é rever a recepção crítica do romance $O$ amanuense Belmiro, de Cyro dos Anjos, que destaca as relações entre o texto ficcional e os elementos que fizeram parte da biografia intelectual do escritor. Os artigos da recepção no jornal que fizeram parte do contexto de produção desse romance e a crítica acadêmica (subdividida em sociológica e cultural) serão aproximados a trechos de entrevistas publicadas do autor. Por meio dos conceitos de espaço autobiográfico e contrato de leitura retirados de Philippe Lejeune, espera-se identificar os fragmentos biográficos desse romance memorialista, além de observar seus desdobramentos no discurso crítico.

Palavras-chave: Recepção crítica, espaço autobiográfico, contrato de leitura.

\section{ABSTRACT}

The objective of this paper is to review the critical reception of the novel $O$ amanuense Belmiro, written by Cyro dos Anjos. This reception highlighted the relationship between the fictional text and elements that were part of the intellectual biography of the writer. The corpus of this research, which is limited to newspaper articles that were part of the context of production of the novel, and the academic reception, subdivided into sociological and cultural, will be confronted with the author's voice, taken from excerpts of his published interviews. Using the concepts of autobiographical space and reading contract from Philippe Lejeune, we expect to identify the biographical elements of this novel memoir, and to observe their consequences in critical discourse. Keywords: Critical reception, autobiographical space, reading contract.

Um perfil? Você começa por um pedido difícil. Para ser exato, o perfil há de abarcar o indivíduo no tempo, e eu não sei até que ponto o meu perfil de agora se assemelha aos das quadras passadas. A gente muda como as águas do rio de Heráclito, não acha?

Cyro dos Anjos

Edla Van Steen inicia a entrevista a Cyro dos Anjos pedindo que traçasse um perfil autobiográfico em poucas palavras; entretanto, o escritor reconhece a dificuldade de realizá-lo porque considera a sua descrição indissociável das transformações do indivíduo no tempo.

Da mesma forma, o narrador de $O$ amanuense Belmiro, romance de estreia de Cyro dos Anjos, procura esboçar uma escrita autobiográfica no seu caderno de notas. O objetivo inicial das memórias de Belmiro Borba, que seria recuperar o passado provinciano, fracassa em função dos acontecimentos da cidade que o fazem modificar a sua "leitura" ou interpretação de si mesmo.

A concepção de escrita autobiográfica em Cyro dos Anjos associa a figura do "autobiógrafo" à do leitor e, indo mais além, à do próprio intelectual moderno — o que acaba por interferir no discurso crítico da recepção. A figura lacunar de Belmiro e os fragmentos autobiográficos do romance permitem que a recepção produza seu discurso sob a influência dos contextos histórico e ideológico de cada crítico. Seguindo os conceitos de espaço autobiográfico e pacto fantasmático retirados de Philippe Lejeune, é

\footnotetext{
${ }^{1}$ Mestrado em Teoria da Literatura pela Universidade Federal de Minas Gerais. Pesquisa desenvolvida no Acervo de Escritores Mineiros do Centro de Estudos Literários da UFMG sob a orientação do Prof. Dr. Reinaldo Martiniano Marques. E-mail: anandanehmy@gmail.com
} 
possível observar que a aproximação entre os planos biográfico e ficcional, identificada nos artigos e ensaios da recepção, projeta-se a partir desse espaço de leitura que é influenciado pela ilusão referencial.

O corpus desta pesquisa se restringe aos artigos e ensaios da recepção crítica que seriam articulados aos comentários do autor referentes ao Modernismo e à sua produção literária. Pretende-se estabelecer um espaço autobiográfico de leitura do romance que considere o confronto da voz do autor, presente em entrevistas, com os projetos culturais ou políticos esboçados nos estudos da recepção jornalística e acadêmica de $O$ amanuense Belmiro.

A recepção do jornal retoma os conflitos culturais que se desdobravam nos espaços de produção e divulgação literária do Modernismo, influenciando a escrita de $O$ amanuense Belmiro. As características da produção de textos no jornal são incorporadas ao romance que fragmenta o leitor e autobiógrafo, além de associá-los na própria figura do narrador. Distanciada desse contexto, as críticas sociológica e cultural procuram associar a figura do narrador ao intelectual moderno observando as relações entre temas, figuras e contexto ou objetos culturais de valor biográfico. O estudo nos arquivos literários permite que a crítica cultural amplie as possibilidades de interpretação da crítica sociológica ao relacionar a imagem fragmentada do escritor moderno presente nesses objetos biográficos com os temas e figuras que se desdobram no romance.

A associação da leitura à escrita, da figura do autor à do leitor e a referência aos processos materiais de produção do livro constituem temas abordados no romance de Cyro dos Anjos, que trata dos conflitos da geração de escritores modernos na Belo Horizonte de 1930. Ao contrastar os diferentes contextos de recepção, é possível identificar como cada crítico lê a figura de Belmiro ou do intelectual moderno associando pressupostos teóricos às ideologias e aos projetos culturais ou estéticos implícitos nos seus discursos críticos.

\section{A Recepção Crítica no Jornal}

Cyro dos Anjos iniciou a escrita de $O$ amanuense Belmiro com uma série de crônicas que foram publicadas no jornal $A$ Tribuna sob o pseudônimo de Belmiro Borba. Segundo Newton Prates, essas crônicas teriam desvinculado a figura do escritor do personagem. Na coluna diária do Estado de Minas, assinada por W., Prates critica uma das crônicas de Cyro dos Anjos, que transforma Belmiro em "dentista”, com "consultório na Serra":

Dentista, ocupação muito prática, não era a vocação de Belmiro, protestamos exigindo do cronista maior respeito pelas tendências do seu personagem, advertindoo de que Belmiro Borba já adquiria personalidade autônoma, independente, que não podia se submeter aos caprichos, às liberdades do seu criador (PRATES, 1966, p. 2).

Seguindo as sugestões, Cyro dos Anjos reconhece a autonomia de seu personagem, retira "a placa de dentista da porta de Belmiro" e o faz retornar aos "contratempos sentimentais" e "divagações poéticas”. Na época em que o livro começou a ser esboçado, Newton Prates afirma que influenciou outras alterações no romance, tais como o envelhecimento de Belmiro para dez anos e o transporte da ação romanesca do Rio de Janeiro para Belo Horizonte. 
O jornalista relata também uma situação curiosa. Estudantes cariocas da Faculdade de Filosofia, em vésperas de excursão à capital mineira, o procuraram para que, na sua condição de mineiro, respondesse onde ficava a Rua Erê, lugar onde morava Belmiro Borba no romance de Cyro dos Anjos. Segundo Newton Prates, esse fato teve como consequência a incorporação dos lugares onde viveu Belmiro à "geografia sentimental de Belo Horizonte".

Philippe Lejeune (1975) concebe a autobiografia como um gênero textual que funciona a partir da noção de contrato de leitura. Revendo a concepção do discurso em Benveniste, Lejeune propõe que o leitor utiliza o nome próprio como operador de leitura que permite associar a pessoa ao discurso. $\mathrm{O}$ nome próprio do autor reenvia o leitor à figura de uma pessoa real (escritor), estabelecendo o contrato de leitura já explícito nos elementos pré-textuais do livro.

O pacto autobiográfico pressupõe a identidade do nome próprio do autor, do narrador e da personagem. Já o pacto romanesco diferencia o nome próprio dessas três figuras, ou torna apenas idênticos os nomes próprios do narrador e da personagem. Contudo, o pacto fantasmático, que consiste na forma indireta do pacto autobiográfico, retoma os contratos e os pactos de leitura da autobiografia e do romance. Para Lejeune, o espaço autobiográfico é delineado a partir do contraste e da aproximação entre o texto autobiográfico e o romanesco, possibilitando leituras duplas do texto ficcional. Na percepção desse espaço, o leitor não lê os romances apenas como gênero que mostra a verdade da natureza humana, mas também como fantasma revelador de um indivíduo, o escritor.

Ao escolher o nome próprio do personagem, Cyro dos Anjos produz também o espaço autobiográfico no jornal e no livro. O escritor comenta o "processo de gestação" do personagem: "O pseudônimo virou personagem, e personagem-autor, no qual se projetava, em parte, o autor verdadeiro. De pseudônimo converteu-se, assim, em heterônimo" (ANJOS, 1982, p. 16). Inicialmente, nas crônicas de jornal assinadas sob o pseudônimo Belmiro Borba, a composição desse nome próprio configura o pacto autobiográfico no texto, já que, nesse caso, a função do nome é esconder, do público, a figura do autor. Após a publicação do livro, o pseudônimo se torna o nome do personagem-narrador ou heterônimo, desvinculado do nome próprio do autor.

O uso da definição de heterônimo pelo autor mineiro retoma a posição de Newton Prates, segundo a qual o personagem Belmiro Borba se tornara independente do seu criador. Entretanto, é difícil desfazer a associação das figuras do narrador e do autor porque ambos exercem a atividade de escrita, seja no plano ficcional ou na realidade. Para Wander Melo Miranda (1992, p. 38), o pacto fantasmático, que realça “o desdobramento do autor em figuras e "personagens”, permite entrever, já em processo, a noção de autor como um ser de papel”, e da autobiografia como "uma forma de encenação ilusória de um eu exclusivo".

Ao rever Lejeune, Wander Melo Miranda propõe que a autobiografia seja caracterizada como um "ato de discurso literariamente intencionado", que se define através dos "mecanismos internos de organização textual" em articulação com a sociedade e a literatura. Cada autobiografia apresenta uma noção de indivíduo, que é elaborada pelos atos de discurso. Nessa perspectiva, a forma particular de definir a noção de indivíduo contribui para "o endosso ou desmascaramento da ilusão autobiográfica".

A composição do personagem-narrador, tanto no jornal como no livro, rompe com a noção de autoria como exclusividade de um escritor, na medida em que outros escritores interferem na criação ao 
sugerir alterações. Paradoxalmente, o romance retoma a experiência vivida do contexto histórico de Cyro dos Anjos, configurando a ilusão autobiográfica no gênero romanesco através do pacto fantasmático.

Seguindo o conceito de pacto fantasmático, observa-se que o nome próprio do autor (Cyro) ressoa no pseudônimo (heterônimo) Belmiro, mesmo o autor fazendo alusão ao nome do poeta mineiro Belmiro Braga. Cyro dos Anjos afirma, em entrevista à Edla Van Steen (ANJOS, 1982, p. 16), que a aliteração dos dois "Bés" nasceu da simpatia que lhe inspirou a figura do poeta Belmiro Braga. A aliteração, que é um processo comum do autor para elaborar os nomes próprios dos personagens, surge intencionalmente no nome próprio e no sobrenome do narrador.

Além dessa filiação literária ao poeta, também há uma ligação com o personagem machadiano por meio da escolha do sobrenome Borba, retirado de Quincas Borba. No caso da filiação literária, Cyro dos Anjos se revela um leitor da tradição seguida por Machado de Assis que a incorpora ao compor o personagem Belmiro Borba.

A recepção crítica de $O$ amanuense Belmiro, que, assim como o livro, inicia-se no jornal, lida com o tema da diferença e (ou) da semelhança das escritas de Machado de Assis e Cyro dos Anjos. Ao mesmo tempo, a recepção já esboçava uma leitura do pacto fantasmático ao abordar elementos biográficos do romance em seus artigos. As influências literárias, o estilo, a oposição entre os romances psicológico e social são temas retomados nessas críticas de jornal.

\section{Elogios e críticas nos jornais}

O artigo "Elogio da obra bem escrita", de Eduardo Frieiro, sintetiza os problemas na concepção do conceito de estilo elaborado pela crítica de jornal. O título do artigo já indica que a "obra bem escrita" é o valor literário dessa concepção de estilo. Se escrever bem significa ter valor literário, para o crítico Eduardo Frieiro a mesma característica é mal vista por parte da crítica: "Dizer que alguém escreve como Machado de Assis, soa como vitupério, na opinião de muitos. Na de outros vale como um grande elogio. Para outros, ainda, significa um louvor mitigado" (FRIEIRO, 1938, p. 3).

Contudo, Frieiro não se limita a elevar o nome de Cyro dos Anjos à categoria de criador, pois afirma que a sua escrita segue a obra de Machado de Assis como modelo. Ambos os autores se encaixariam na linhagem que, sem eliminar o estilo, apresenta uma escrita "harmônica" e "elegante", ou seja, seguem o modelo normativo de escrita proveniente de autores antigos (ou até alguns modernos), linhagem oposta a de escritores que, ao romperem com a norma, são classificados como criativos.

Ao defender o estilo de Cyro dos Anjos, Frieiro trata do conflito dos intelectuais modernos com a tradição e os valores literários, defendidos pelos partidários ou não das inovações estéticas do Modernismo, expondo também a sua oposição à literatura de caráter social:

Os modernistas brasileiros da revolução literária de 1922 insurgiram-se contra os escritores apurados e as obras bem escritas. Os escritores populistas ou proletarizantes, vindos depois, erigiram em princípios de arte e linguagem rasteira e a forma desordenada. Os escritores acadêmicos ou simplesmente corretos foram desprezados e injuriados como passadistas (FRIEIRO, 1938, p. 2). 
O artigo de Rubem Braga (1938) segue outra perspectiva referente à influência machadiana e ao romance social. Logo na primeira frase do artigo, Braga apresenta o romance de Cyro dos Anjos como "memorial machadiano de um funcionário público de Belo Horizonte envenenado de literatura, e vivendo em um círculo muito estreito de relações e afetos" (1938, p. 4). A semelhança desses autores é o gênero memórias, mas a diferença essencial é a profissão do narrador em Cyro dos Anjos. Braga marca as diferenças entre os autores a partir do contexto histórico que é avaliado pelo crítico como mais aflito em $O$ amanuense Belmiro, mesmo que o narrador seja indiferente e fuja das aflições sociais, elas "invadem a sua toca e conquistam um lugar no seu drama”.

Assim, o romance de Cyro dos Anjos não é apenas psicológico, mas apresenta aspectos sociais que são esboçados pela retomada de elementos do contexto histórico: as aflições tratadas no romance são de um funcionário público que vive as voltas com uma roda de literatos. A descrição desse meio literário é familiar para Rubem Braga, que compõe o seu estudo crítico sugerindo o espaço autobiográfico de leitura do romance ao tratar das figuras do livro. Na perspectiva do crítico, os personagens do romance seriam fixados em tipos artificiais como Glicério, que representa a humanidade banal; Silviano, o homem complicado; Florêncio, que conta anedotas; e Redelvim, encarregado de ser comunista.

O ponto fraco do livro, segundo Rubem Braga, seria o excesso de explicação das personagens. Porém, faz a ressalva de que seu estudo foi feito "ataboalhadamente" e "perturbado" porque conhece o meio e as pessoas reais que serviram de "modelo" e, mais ainda, "sugestão" para o livro. Rubem Braga lê o espaço autobiográfico do romance, contrastando a escrita de Cyro dos Anjos às figuras reais que compunham o cenário cultural da roda de intelectuais frequentada tanto pelo próprio crítico como pelo escritor mineiro. Dessa forma, sua leitura crítica exige o pacto autobiográfico, mas constata a presença do pacto fantasmático na não verossimilhança dos personagens frente às figuras reais.

É comum a recepção crítica de Cyro dos Anjos apresentar classificações que diferenciam a produção do norte, caracterizada como literatura social, da produção do sudeste e do sul, mais introspectiva. Mário de Andrade (1939) contrapõe-se a essa perspectiva, revendo a rígida classificação dos romances. No título de seu artigo, "Psicologia em análise", Andrade discute o critério de definição do que é um romance psicológico, que será revisto em suas contradições, ou melhor, seguindo o próprio jargão da psicologia, será analisado pelo crítico. Assim, a análise está presente em romances do norte, do sul e sudeste, em Machado de Assis e nos comediantes.

A crítica, ao descrever a psicologia dos personagens, classifica os romancistas em duas categorias: de um lado, os autores que "preferem fazer psicologia em ação, frases e gestos dos seus personagens", de outro, os que preferem a "análise direta e introspecção, o registro da dinâmica física independente da ação". Para Mário de Andrade, que não concebe essas distinções como intransponíveis, os romances de Rachel de Queiroz e Thelmo Vergara têm momentos de análise, assim como José Lins do Rego, com uma narrativa mais analítica, não deixa de apresentar ação. 


\section{Leituras de Influências e Inovações}

Outro exemplo dos limites da classificação romanesca é a comparação entre Cyro dos Anjos e Graciliano Ramos (que voltam suas escritas para a vida interior) e entre o autor mineiro e a suposta influência machadiana. A análise, entretanto, é mais característica em Angústia, de Graciliano Ramos, do que em Cyro dos Anjos, que foi mais influenciado pelo humorismo. Mário de Andrade questiona a tendência da crítica literária que identifica a influência de Machado de Assis apenas fazendo referência ao humorismo de Cyro dos Anjos. Essa tendência parte do pressuposto de que ser humorista é sinônimo de ser machadiano, mas Andrade lembra que essas características ditas machadianas já se encontravam nos humoristas ingleses e franceses.

A escrita de Raquel de Queiroz, segundo Mário de Andrade, é mais próxima de Machado de Assis do que a de Cyro dos Anjos. No romance Três Marias, a autora apresenta "a lapidação cristalina da frase" e "o próprio mecanismo de pensar" que são características da escrita machadiana. A perspectiva crítica de Andrade, de caráter etnográfico, revela quais são os valores literários da crítica ao estipular classificações que nem sempre se prendem aos aspectos linguísticos que caracterizariam as diferenças ou semelhanças dos escritores.

Para Helena Bomeny (1994, p. 74), a necessidade de inovação dos intelectuais modernos vem acompanhada dos conflitos gerados pela busca de uma identidade e de um projeto nacionais que apresentem também uma feição universalista. Diferenciando-se do grupo de São Paulo, que seguia a influência do nacionalismo romântico, o grupo mineiro tendia para a tradição machadiana e a literatura francesa (sobretudo Anatole France). Contudo, esses grupos de intelectuais, simultaneamente, aproximavam-se e rompiam com a tradição. Ainda, buscavam registrar a cultura nacional, mas faziam ressalvas quanto à representação do social na literatura regionalista.

Assim, a crítica de rodapé retoma as questões que fizeram parte do contexto histórico desses grupos intelectuais ao identificar, valorizando ou não, as influências literárias de Cyro dos Anjos e ao definir o gênero do livro como romance psicológico, confrontando-o ao "romance social”, ou pondo em dúvida essa distinção de gêneros. As entrevistas de Cyro dos Anjos apresentam também o julgamento do autor em relação à influência da escrita machadiana. Nelas, contudo, o autor foca a questão da influência em ângulos diversos que, quando confrontados, indicam as tendências culturais predominantes na época de cada entrevista.

\section{Nas Entrevistas o Autor Desconfia}

Em entrevista da década de 1940, Otto Lara Resende (ANJOS, 1944, p. 4) provoca Cyro dos Anjos ao perguntar o que o autor pensa a respeito de grande parte da “crítica indígena” classificá-lo como “um Machadiano". Para o autor mineiro, sua escrita não se situa sob esse meridiano, que se caracterizaria pelo elemento intelectual, pela ausência de lirismo, o jogo de conceitos e a forma barroca; porque, segundo ele, $O$ amanuense Belmiro é fundamentalmente um "livro sentimental". 
Cyro dos Anjos explica que os críticos fazem essa aproximação baseando-se em critérios puramente formais, "isto é, pela analogia entre processos técnicos empregados no "Amanuense" e em alguns livros de Machado de Assis" (1944, p. 4). Esses processos, que foram avaliados pelos críticos pela sua materialidade, não seriam criações exclusivas de Machado de Assis, "pois têm sido utilizados por escritores de todas as literaturas" (1944, p. 4). Essa concepção de estilo da crítica, segundo analisou o autor na entrevista, parte da separação entre forma e fundo (ou expressão), ou matéria. O modelo de escrita é, segundo a crítica, Machado de Assis, mas, para o autor, a forma classificada como machadiana pertence à "Literatura Europeia".

Separando forma e conteúdo, Cyro dos Anjos afirma o caráter sentimental de seu romance como desvio da norma. A desconfiança de Cyro dos Anjos quanto às comparações do seu estilo com o machadiano são justificáveis na medida em que o conceito de estilo da crítica não explica a origem da forma de escrita utilizada por ambos os autores, sem os inserir em uma tradição universal. Contudo, essa insatisfação é momentânea.

Em entrevista a Giovanni Ricciardi, referente à década de 1990, Cyro dos Anjos afirma que foi leitor de Machado de Assis e recebeu influência muito forte de seu estilo. Nesse contexto, o autor assume o uso da tradição machadiana. Na data de publicação do livro (1937), os escritores experimentavam os conflitos e as dualidades da segunda fase do modernismo, que fazia a crítica da tradição, incorporando-a.

$\mathrm{Na}$ entrevista a Ricciardi, Cyro dos Anjos já se firmou como escritor moderno. A fala do entrevistado é persuasiva porque pretende atingir ao terceiro interlocutor. Nela se encontra a imagem de "autor" que o próprio entrevistado deseja configurar para o seu público alvo. Na primeira entrevista, o autor nega a influência machadiana para inserir ambos os autores na literatura universal, na segunda entrevista, ele já afirma a influência de Machado de Assis e se insere na tradição literária nacional.

As entrevistas apresentam também a posição do autor quanto à presença ou não de elementos sociais na sua obra. Para Otto Lara Resende, Cyro dos Anjos afirma que "um escritor não pode viver fora de sua época", pois "a questão social é um tema de todos os tempos". Entretanto, o autor critica o uso artificial dos problemas sociais nas obras literárias que deveriam abordá-los de forma espontânea, quando a situação no livro assim exigisse.

$\mathrm{Na}$ entrevista à Edla Van Steen (1982), Cyro dos Anjos afirma que no seu romance procurou "retratar um indivíduo, não uma classe". Isso porque "na classe, o indivíduo se perde" e a sua preocupação é o homem em sua solidão. A posição do autor é contrária à crítica de Rubem Braga. O crítico avalia os personagens do romance como figuras vazias encarregadas de fazerem justamente o contrário do que o autor mineiro quer, ou seja, representam uma classe, mas de forma limitada.

A contradição entre aquilo que o personagem é no seu cotidiano - burguês, fascista, comunista, feminista, homem comum - e as suas ideias produz no leitor o efeito de desconfiança na própria ideologia. Dispostos em discursos ideológicos diversos, o conflito entre os "amigos" levaria à desagregação e à "solidão" do indivíduo que não se adapta ou não incorpora o discurso do outro ao seu próprio discurso. Belmiro se opõe ao confronto, que levaria a consequente dissolução do grupo de amigos: "De que valem esses choques entre amigos? Cada um continua onde está, aferrado às suas ideias. Tanto mais aferrado se as contraditamos" (ANJOS, 1937, p. 139). 


\section{$A$ impossível coerência}

O capítulo "Choques" apresenta uma das constantes discussões do narrador com o personagem Redelvim. Os amigos se olham com estranhamento: para Belmiro, Redelvim é um "comunista romântico", inofensivo, enquanto o amigo vê o narrador como um "pequeno burguês" cético. O diálogo se inicia com uma provocação de Redelvim: "Então, continua nessa vidinha sórdida de pequeno burguês?”. Belmiro não assume a identidade e ironiza: “Tem cem mil réis para me emprestar? (realmente estava precisando)". O personagem Redelvim, ainda prossegue a discussão, observando que ser burguês é um estado de espírito.

Nessa perspectiva, o estado de espírito do sujeito é definido por mais um campo discursivo que se volta para a ideologia capitalista. Trata-se de um campo contraditório na medida em que não vincula necessariamente o sujeito classificado como burguês à posse material do dinheiro. Mais contraditória ainda é a própria definição política de Belmiro, que se autodenomina um "individual-socialista”. É uma tentativa de incorporar o discurso do outro na sua própria definição política, atenuando a imagem de "pequeno burguês", mas isso não significa que o amigo comunista aceita a retórica do amanuense.

Redelvim e Belmiro, apesar das diferenças, têm semelhanças importantes que instigam ainda mais o conflito dos amigos. No capítulo "Onde se apresenta um revolucionário", a visita de Redelvim a Belmiro trata das dívidas mútuas dos personagens e de uma confidência. Segundo o narrador, Redelvim o visitara para colher um duplo "aval". O primeiro consiste em reformar a promissória com o amanuense e o segundo é confessar que participa de um movimento político cujo desfecho seria a "revolução proletária”. Comenta também que a polícia invadira o partido e tomara os documentos com a relação dos membros, entre eles, o nome de Redelvim na lista. Durante a conversa, Belmiro se mostra preocupado com o amigo; Redelvim, contudo, avalia essa preocupação como "pequeno burguesa" para, em seguida, afirmar que "os indivíduos nada significam, segundo o seu modo de pensar". Mais próximo do discurso marxista referente às classes sociais, Redelvim rejeita o individualismo que se filiaria ao capitalismo.

Esse fato é relatado pelo narrador com o uso de palavras que retomam o sistema financeiro de forma direta, como "promissória", ou indireta, na palavra "aval", que tem sentido duplo, referindo-se tanto a apoio moral e intelectual como a termo comercial ou ordem de pagamento. A visita de Redelvim se finaliza com sua saída para o banco. Mesmo a conversa atravessada por conflitos ideológicos e pelo tema da "revolução proletária", os personagens ainda se prendem às ações cotidianas que fluem com o uso do dinheiro.

Daí a ironia no título citado: o revolucionário Redelvim se apresenta na casa do amanuense, pequeno burguês, para refazer uma promissória, o que significa que até as ditas ações políticas dependeriam do financiamento "burguês". Assim como a Revolução Francesa foi fomentada pela burguesia, a atividade política de Redelvim também tem um sustentáculo financeiro semelhante ao do amanuense "burguês". Trata-se do Estado, afinal, como relata o narrador, Redelvim fora seu companheiro nas "aperturas financeiras e na burocracia". Mesmo tendo deixado o funcionalismo porque 
se desentendeu com o diretor da repartição, Redelvim trabalhava em jornais que, no contexto histórico do autor na década de 1930, também se associavam ao Estado, defendendo os interesses do governo.

As figuras de Belmiro e Redelvim constituem um duplo que permite leituras baseadas no pacto fantasmático porque retomam a figura do intelectual moderno, dividida entre a atividade literária e a função pública, seja como pequeno funcionário de seção, seja na tarefa de jornalista. Inserido no mesmo contexto histórico de Cyro dos Anjos, exercendo também a atividade jornalística, Rubem Braga desconfia justamente da intenção do autor de retratar os indivíduos.

O narrador antevê a impossibilidade do sujeito, filiado ao socialismo ou ao capitalismo, de manter a coerência entre a ideologia que defende e a sua própria existência material no mundo. Mas Redelvim insiste em ser coerente, entretanto, nas questões cotidianas, como observa o amanuense, não consegue coerência com a sua ideologia e não se conscientiza das suas próprias contradições, fato esse que explica o artificialismo do personagem. Belmiro é um personagem que aceita e vivencia suas contradições e, talvez por isso, seja também aceito por Rubem Braga como "o único literato que de fato interessa no livro".

O diário íntimo é gênero trabalhado na escrita fictícia de Belmiro Borba, que serve para reflexões sobre a leitura e tema para a literatura personalista do narrador. Antes de ser um autor do seu diário, Belmiro Borba é leitor do diário de seus amigos Redelvim e Silviano: "Redelvim também tem o seu "Diário... Li páginas dele, há tempos, pelo mesmo processo clandestino por que conheci o do Silviano" (ANJOS, 1937, p. 151). O diário, gênero de origem burguesa, é o meio de escrita utilizado por Redelvim que não traz anotações explicitando o seu perfil político, mas, segundo Belmiro, tratam da sua "individualidade": "Como todos os documentos dessa natureza, contém histórias muito íntimas, amores (inclusive o caso de sua amante espanhola, que o torturou bastante) e versos de adolescência. Redelvim não permite que se lhe fale dos amores nem dos poemas" (ANJOS, 1937, p. 151).

Descrito como literato, filósofo, fascista, mitômano, Silviano é um personagem "múltiplo" para o narrador e seus amigos. Belmiro também faz leituras clandestinas do diário de Silviano, contudo, cita trechos e incorpora-os na sua própria escrita. O conteúdo do diário de Redelvim é apenas apropriado no discurso indireto do narrador em um pequeno parágrafo. A narrativa não apresenta uma explicação para a escolha, mas o que pode ficar como questão é que a escrita de Redelvim é silenciada pelo narrador, que prefere citar na integra, para, em alguns momentos, ridicularizar, a escrita de Silviano.

A escrita de Belmiro Borba, que se apropria dos diários alheios, tem os seus momentos de silêncio, ocasionados ou não pelos interesses do autor empírico. Contando com o contexto histórico do Estado Novo, é provável que as figuras de Belmiro e de Silviano fossem mais bem acolhidas pelos meios de publicação do que a de Redelvim.

O memorialista Belmiro configura a multiplicidade de sua voz narrativa, que ora é cindida no par escritor / funcionário público, ora é elaborada a partir das vozes e textos de outros personagens. No jornal, que sujeita o texto literário a vários tipos de leitores, Cyro dos Anjos convive com a pluralidade da recepção que esse veículo permite. $\mathrm{Na}$ escrita do romance, o autor multiplica a figura do leitor modelo, que vai desde o "vago leitor", que pode ser qualquer um, até o leitor par, que é a "âme-soeur", ou o "leitor futuro", que lerá o diário publicado. 
A observação dos arquivos que trazem informações sobre o contexto histórico e cultural da produção literária, amplia as possibilidades de leitura do romance memorialista como objeto que se configura a partir da relação entre o intelectual e os meios de divulgação do texto. Assim, os contrastes entre as leituras de Newton Prates, de Rubem Braga e de Mário de Andrade confirmam as reflexões do personagem Belmiro sobre a própria composição do diário que, antes de revelar a unicidade do escritor e do leitor de memórias, delineia a fragmentação e as contradições do sujeito nos planos de produção e recepção do texto literário.

\section{A Recepção Acadêmica}

A recepção crítica de $O$ amanuense Belmiro renova as reflexões teóricas referentes à oscilação da voz narrativa no par funcionário público/escritor, principal foco dos críticos que identificam a presença de elementos biográficos que configuram o pacto fantasmático no romance. Questões que já foram esboçadas nas leituras de Rubem Braga e Mário de Andrade são retomadas no contraste entre a recepção marxista, que utiliza como arcabouço teórico a dialética entre texto e contexto ou o realismo crítico de Georg Lukács, e a crítica cultural, que faz referência aos teóricos pós-modernos como Gilles Deleuze e Michel Foucault, além de buscar outras linhagens literárias ou filosóficas para o romance de Cyro dos Anjos.

É possível estabelecer uma comparação entre as leituras marxistas e culturais de Cyro dos Anjos e o estudo Realismo crítico hoje, de Georg Lukács (1969), que trata da concepção de mundo de dois grupos de escritores que fazem parte da literatura burguesa contemporânea. Lukács distingue os escritores realistas, no qual inclui Thomas Mann, dos escritores de vanguarda, grupo que abarca escritores como James Joyce, Kafka e principalmente Robert Musil. Essas correntes literárias apresentam, segundo Lukács, diferentes concepções do homem e da realidade efetiva.

Assim, na literatura realista, as circunstâncias histórico-sociais determinam e condicionam o destino dos personagens. A possibilidade abstrata de realização pode tornar-se concreta na perspectiva realista, configurando a irrupção do drama na realidade efetiva. Por outro lado, na literatura de vanguarda, tem-se o predomínio da possibilidade abstrata, que é mais rica do que a realidade. A literatura de vanguarda realiza o movimento do "sujeito que conhece" enquanto a literatura realista realiza o movimento da "realidade efetiva" conhecida pelo sujeito. Lukács diferencia essas correntes estéticas observando o desenvolvimento ou a suspensão da ação na narrativa.

O imobilismo e a atitude intelectual de Belmiro permitem aproximá-lo da corrente literária de vanguarda, trabalhada por Lukács. É necessário lembrar que a classificação do realismo crítico foi utilizada pela recepção acadêmica com o fim de estabelecer uma crítica paralela ao papel limitado do intelectual moderno no âmbito político do seu contexto histórico. Partindo-se de um sujeito histórico determinado, que é o funcionário público-escritor, alguns estudos críticos do romance associam a figura do narrador à do autor empírico. 
Antonio Candido e Roberto Schwarz abordam o estudo da narrativa sob o enfoque da crítica marxista. Em "Estratégia", Antonio Candido destaca as diferenças entre Machado de Assis e Cyro dos Anjos:

Enquanto Machado de Assis tinha uma visão [...] dramática, no sentido próprio da vida, Cyro dos Anjos possui, além dessa, [...], um maravilhoso sentido poético das coisas e dos homens. O que é admirável no seu livro, é o diálogo entre o lírico, que quer se abandonar, e o analista, dotado de humour, que o chama à ordem; ou, ao contrário, o analista querendo dar aos fatos e aos sentimentos um valor de pura constatação, e o lírico chamando-o à vida, envolvendo uns e outros em piedosa ternura (CANDIDO, 1945, p. 87).

O crítico parte do princípio de que a dialética entre texto e contexto delineia a figura do intelectual moderno na narrativa. A oscilação do narrador entre o lirismo e a análise é uma crítica à limitação do intelectual na sociedade, que não consegue concretizar suas ideias no plano real. Antonio Candido define o elemento dramático da narrativa como um reflexo da solução intelectual de Belmiro a sua desadaptação ao mundo: "refugia-se no passado, uma vez que o presente lhe escapa das mãos. [...] O drama é que o presente se insinua no passado" (1945, p. 85).

Roberto Schwarz utiliza o realismo crítico de Georg Lukács como arcabouço teórico seguindo a distinção anteriormente citada entre os escritores engajados e os de vanguarda. O escritor engajado realiza a representação de uma consciência coletiva, enquanto o escritor de vanguarda se prende ao esteticismo e ao subjetivismo imediato. Nessa perspectiva, a obra literária do escritor engajado expressaria uma visão de mundo que é condição essencial para a ação, tendo o poder de refletir traços da realidade com o objetivo de desalienar o público.

Em "Sobre $O$ amanuense Belmiro", Schwarz observa que o andamento variável do ritmo na prosa entre análise e lirismo interfere no desenrolar da ação. Quando o narrador oscila nesse par, a ação não se desdobra num plano dramático: trata-se, portanto, de "Estética de Acomodação". Schwarz conclui que “o romance da urbanização, que por sua natureza deveria ser dramático, torna-se lírico, na perspectiva intermediária do burocrata" (1966, p. 170). O crítico ameniza seu discurso afirmando que, embora as oscilações da narrativa sejam limites, não são defeitos, já que o romance é escrito na forma de diário. Segundo Schwarz, na construção romanesca, "a biografia de Belmiro é um princípio lírico” que evoca o passado, mais do que senso de conflito e destruição e de crise, é decomposição do presente: "O irremediável não está na perda, está na continuidade; os traços não variam, varia apenas a sua acentuação" (SCHWARZ, 1966, p. 170).

Cyro dos Anjos e Machado de Assis apresentam características comuns em relação ao gênero romance memorialista - e ao estilo. No estudo referente ao livro Memórias póstumas de Brás Cubas, porém, é possível observar que existe uma preferência de Schwarz (2000, p. 11) pela narrativa machadiana. O crítico cita Machado como exemplo de poética que dramatiza o espetáculo social do país, sendo possível classificá-lo como escritor engajado. Nessa perspectiva, a ausência da ação dramática na escrita de Cyro dos Anjos é o que o distingue de Machado de Assis.

Ao citar o gênero memórias como característica que justifica as "platitudes" de Belmiro, Schwarz procura disfarçar o tom negativo da sua crítica literária. Contudo, o crítico destaca importantes 
contradições nas falas do personagem-narrador que se nega a classificar o homem segundo doutrinas, mas põe-se na defesa do seu trabalho, desfazendo parcialmente o seu ceticismo: "A prova do contrário está em mim. Atuo no meu setor, como se acreditasse nas coisas. As necessidades vitais fazem o homem agir e não permitem que ele se torne um contemplativo puro" (ANJOS, 1937, p. 168). Para Schwarz, Belmiro confunde ganha-pão com ativismo e afirma a "inexistência" das diferenças sociais. O crítico define a burocracia como "a pedra seca do amanuense" que confirma a permanência do privilégio rural estendido à "sinecura" da Seção de Fomento, onde Belmiro consegue trabalho através dos favores de um deputado.

Schwarz conclui que o imobilismo de Belmiro é uma consequência da queda de sua linhagem rural. Nessa perspectiva, o narrador se "desqualifica" ou "perde seu prestígio" político e familiar passando da aristocracia rural para o serviço público. Para Schwarz, a oscilação do narrador no passado e presente ou nos espaços rural e urbano não permite uma articulação do tempo, que é subjetivado e governado pela memória e divagação: a imobilidade constituiria uma forma negativa de conciliação que figura no final do livro.

Mesmo definindo Belmiro como "o parado", Silviano Santiago não avalia a passagem para o serviço burocrático e para a cidade como desqualificação. Nessa leitura crítica, Belmiro é um narrador que não se decide: "Enquanto protagonista, ele é um indeciso no tempo e no espaço da genealogia e no tempo e espaço rural e citadino" (SANTIAGO, 2006, p. 67). Para Santiago, a leitura de Schwarz, que alterna a figura do narrador em espaços opostos, procura, na verdade, adaptar "o final brusco do romance a desígnios ideológicos, uma 'forma negativa de conciliação' ” (SANTIAGO, 2006, p. 38).

Em $A$ vida como literatura, Silviano Santiago destaca as referências do romance às literaturas francesa e nacional, representadas nas figuras de Machado de Assis e Carlos Drummond, e à filosofia em Nietzsche. Santiago constata que Cyro dos Anjos faz uso de uma escrita caracterizada pelo hibridismo entre o clássico e a prosa moderna. A influência da literatura tradicional e antivanguardista francesa, representada pelo interesse de André Gide pelo fait divers, possibilita a Cyro dos Anjos "escrever com uma língua nacional castiça e um estilo coloquial enxuto" (SANTIAGO, 2006, p. 66).

Os faits divers são crônicas de acontecimentos diários que apresentam a descrição dos fatos sem artifícios e sem a fantasia literária, além de se caracterizarem pelo uso da escrita do diário e pelo cultivo à contenção estilística. Para Santiago, a psicologia dessa escritura se diferencia das máximas universais que caracterizam a narrativa moralista. O foco dessa nova psicologia é retratar mais "as tramas urdidas pelo outro, imaginário do mesmo, na sua cotidianidade, do que as reflexões feitas pelo próprio escritor na sua biblioteca”. A valorização do cotidiano abarca o tema do escritor que, na pretensa tentativa de se alcançar a verdade humana na escrita autobiográfica, configura uma verdade poética.

Silviano Santiago estabelece diferenças entre o romance de Cyro dos Anjos e a narrativa oitocentista. Sua análise parte do final do romance memorialista de Cyro, que não chega ao fim da vida do narrador. Nesse caso, temos a junção entre o formal (romance) e o existencial (vida). Na grande narrativa oitocentista - Santiago cita Machado de Assis como exemplo - o meio da vida não leva o narrador a fingir que tenha chegado ao fim dela. No caso do romance de Cyro, o meio da vida do protagonista se confunde com o fim do livro. Por outro lado, em Dom Casmurro, o meio do livro coincide 
com o instante em que os fatos narrados chegam ao meio da vida. O crítico cita a metáfora da gestação que relaciona o nascimento ao início da escrita:

Sim, vago leitor, sinto-me grávido, ao cabo, não de nove meses, mas de trinta e oito anos. E isso é uma razão suficiente. Posta de parte a modéstia, sou um amanuense complicado e a vida fecundou-me a seu modo, fazendo-me conceber qualquer coisa que reclama autonomia no espaço (ANJOS, 1937, p. 24-25).

Santiago utiliza a metáfora do estupro para explicar o trecho "a vida fecundou-me a seu modo", justificando a metáfora da gestação. Contudo, analisando esse trecho citado pelo crítico, o modo como a vida fecunda Belmiro não é explicitado. O estranhamento do adjetivo "grávido" implica mais o fato de se estar fazendo analogia entre a gravidez, que é uma função biológica do corpo feminino, e a origem da escrita. A expressão "a seu modo", portanto, pode estar também relacionada à analogia entre a escrita e a gestação, porque quem gesta, no caso do romance, é do sexo masculino.

A leitura de Santiago se apoia no trecho de Roland Dogelès: "é o estupro que salvará o amor", aproximando a ideia de estupro do indivíduo pela realidade a "o momento em que o humano descobre o Amor pela escrita" (SANTIAGO, 2006, p. 15). Os fatos, que fazem parte do plano real, passam, através da metáfora do estupro, para o plano da realidade estruturada simbolicamente. Constitui-se, assim, o duplo imaginário da realidade. Trata-se do modo violento como a exterioridade traumatiza o narrador, "ao deslocar o eixo da vida do plano real para o plano da realidade simbolicamente estruturada" (SANTIAGO, 2006, p. 16-17).

Para Santiago (2006), o romance de Cyro dos Anjos apresenta três figuras dramáticas Belmiro, Carolino e o leitor — que produzem efeitos de sentido. Belmiro, ao recorrer nas epígrafes do romance aos trechos de Remarques sur les mémoires imaginaires, de Georges Duhamel, questiona a própria veracidade da sua escrita memorialística. Duhamel não dá certeza aos seus leitores se suas memórias seriam verdadeiras ou imaginárias. Segundo Santiago, o efeito Duhamel, causado pelas epígrafes, faz o leitor questionar o estatuto de real da literatura autobiográfica, enquanto o efeito Nietzsche, que consiste em olhar o mundo como se fosse uma obra de arte, interfere na própria leitura daquilo que se concebe como realidade. No romance de Cyro dos Anjos, esses efeitos de sentido se acentuam em personagens como Belmiro e Carolino que retomam respectivamente, no plano ficcional, as figuras do autobiógrafo e do leitor. Carolino é um funcionário de baixo cargo da Sessão de Fomento, cúmplice do narrador, que fornece o papel da seção, clandestinamente, para Belmiro escrever suas memórias durante o serviço. $\mathrm{O}$ leitor faz figuração no romance, ora quando é citado por Belmiro, ora quando as falas dirigidas ao Carolino apresentam uma leitura dupla - parecem que são voltadas para o leitor.

Assim como Santiago, Eneida Maria de Souza (2009) identifica o drama do intelectual na escrita memorialista de Cyro dos Anjos, mas busca a filiação de Cyro dos Anjos a autores na literatura universal como Baudelaire, Melville, Kafka, Musil, Borges e Vila-Matas, que, assim como o escritor mineiro, apresentem referências ao tema do nada da existência. Kafka e Musil são autores da estética de vanguarda que retomam a classificação de Georg Lukács.

Para a ensaísta, esses autores, assim como Cyro dos Anjos, dramatizam o tema da "fragilidade de vínculos entre os sujeitos" que levaria ao conflito identitário causado pelos desvirtuamentos dos valores e da fragmentação do “eu com seu 'estranho' outro”. Christine Buci-Gluksmann distingue o efêmero 
cômico de herança nietzscheana, caracterizado pela leveza e positividade, do spleen em Musil e Baudelaire, que se define pelas noções de efêmero e transitório, pela alegorização do ego e da alienação de si. Citando Buci-Gluksmann, Souza observa que a escrita de Cyro dos Anjos apresenta um conceito de arte e sensualidade que afirma a vida como princípio carnavalesco, opondo-se ao princípio formal destrutivo presente no drama barroco que inscreve o efêmero melancólico como fragmento e ruína. A ruptura moderna com a tradição da família, a falência da fazenda e a fragilidade dos vínculos afetivos, compensada no âmbito urbano pelo grupo dos amigos, tornam-se suportáveis para Belmiro que, segundo Souza, adquire saúde através da escrita memorialística.

A recepção sociológica estabelecia o espaço autobiográfico de leitura do romance identificando temas e figuras no plano ficcional que seriam comuns ao plano biográfico dos intelectuais modernos. $\mathrm{O}$ estudo crítico de Souza, que enfatiza a autoria como uma função discursiva, amplia as possibilidades desse operador de leitura na medida em que contrasta o texto ficcional aos objetos do Arquivo Literário de Cyro dos Anjos. As cartas dos escritores modernos com o timbre de órgãos do Estado são comparadas ao papel timbrado da Seção de Fomento, que é o suporte ficcional das memórias de Belmiro. Além do material manuscrito, Souza pesquisa o material iconográfico referente ao segundo Salão de Belas Artes de Belo Horizonte em 1938. Nesse evento, Delpino Júnior, que concorria ao prêmio com o retrato de Cyro dos Anjos, expôs também a figura de Belmiro Borba em desenho, que foi comentada pelo conferencista João Alphonsus. Para Souza, a semelhança das figuras no retrato e no desenho leva Alphonsus a se decidir pelo estatuto de ficção da personagem:

Em tom humorístico, João Alphonsus decide sobre o estatuto de Belmiro Borba como ficção, graças à imagem criada pelo desenhista. Cyro e Belmiro, autor, pseudônimo e personagem se acham expostos no Salão, e adquirem, ainda que imaginariamente, autonomia, no entender do conferencista João Alphonsus (SOUZA, 2007, p. 15).

Comparando-se as diferentes recepções críticas, nota-se que a leitura de Roberto Schwarz é normativa no sentido de estabelecer critérios para especificar o que é o drama social brasileiro. Nessa perspectiva, Machado de Assis seria uma literatura oficial que define o que é drama. Contrapondo-se a essa leitura, Antonio Candido percebe a dramaticidade em Cyro dos Anjos, contudo, volta-se para a questão temporal. Ao relacionar texto e contexto, Candido universaliza a figura do narrador uma vez que o drama do intelectual se situa no plano da heterogeneidade do tempo: para Belmiro, o passado é o refúgio que é constantemente perturbado pelo presente. Nessa leitura, Belmiro não é apenas o intelectual brasileiro que compactua com o Estado Novo — o intelectual da Estética da Acomodação mas é o intelectual moderno que está sujeito ao conflito universalista do tempo.

A crítica cultural não descarta a presença do drama na escrita de Cyro dos Anjos. Para Silviano Santiago, o narrador rompe a unicidade de um eu que se desdobra entre a realidade e a ficção ao dramatizar no papel vidas imaginárias. Em ensaios como "O intelectual modernista revisitado" (1989) e "Suas cartas, nossas cartas" (2002), Santiago pesquisa documentos de escritores em contraste com as respectivas produções literárias e atividades culturais. A partir dessa comparação, o crítico propõe que os "jogos intertextuais" de documentos e leituras críticas da obra de intelectuais modernos contribuem para decodificar temas dramatizados na escrita e história moderna. Eneida Maria de Souza observa a 
encenação do drama do intelectual moderno na narrativa de Cyro dos Anjos, confrontando o romance com os documentos e objetos que fizeram parte da biografia intelectual do escritor.

A crítica cultural apresenta uma perspectiva histórica do drama do intelectual moderno fundamentada no contraste entre o romance e os documentos e objetos culturais que pertenceram ao contexto histórico de produção do livro. Os arquivos literários permitem o desdobramento de questões teóricas que destaquem as preferências literárias dos escritores, identificadas nas coleções bibliográficas, o estudo dos manuscritos na crítica genética, a composição da imagem do escritor em entrevistas e objetos iconográficos, os efeitos da recepção crítica na produção literária e as consequentes alterações no estilo do escritor.

\section{O Leitor e o Tempo}

Mesmo fazendo ressalvas quanto à descrição de um perfil na entrevista, Cyro dos Anjos se apresenta sob uma perspectiva biográfica, informando ao leitor quais são os processos de criação do romance, seu vínculo com a escrita jornalística e o serviço público, sua aproximação com o grupo de intelectuais mineiros liderado por Carlos Drummond de Andrade ou com políticos do Estado Novo no trabalho em gabinetes. O escritor se define a partir das instituições que serviram de origem ou que deram condições materiais para efetivar a sua produção literária. A imagem ambivalente do escritor como funcionário público da ditadura estadonovista, no plano biográfico, faz parte da composição de seu romance de estreia. A interpretação da figura do funcionário público e os efeitos do pacto fantasmático permitem à crítica literária estabelecer relações entre o romance e o contexto do autor empírico que são influenciadas pelo contexto histórico da própria recepção.

Na recepção do jornal, Rubem Braga é o crítico que destaca a relação entre o drama e o contexto histórico de Cyro dos Anjos na produção de $O$ amanuense Belmiro. Na recepção contemporânea, o posicionamento ideológico de cada crítico ainda interfere na percepção do elemento dramático na narrativa. Como crítico engajado que exige a ação do narrador, Schwarz caracteriza Belmiro dentro da estética da acomodação ou do imobilismo de vanguarda. Adepto da estética do pastiche, Silviano Santiago define a escrita memorialística de Cyro dos Anjos, que funde autobiografia e imaginário, como uma reação do escritor à realidade que traumatiza o sujeito. Coerente com seu projeto literário das memórias imaginárias de Graciliano Ramos, Santiago valoriza o personagem Silviano (amigo e alter ego de Belmiro), que faz recurso ao imaginário na construção da sua "autobiografia”. Ampliando a linhagem literária do romance de Cyro dos Anjos, a leitura de Eneida Maria de Souza associa Belmiro Borba a uma série de copistas que retomam o drama do escritor e sua pulsão negativa pela escrita que fazem parte da literatura moderna. Como projeto cultural dos estudos de Santiago e Souza, que fazem referência aos arquivos literários, destacase a importância da preservação de Acervos dos documentos e objetos biográficos dos escritores modernos para a pesquisa em Literatura.

Assim, as leituras de Rubem Braga e Antonio Candido são retomadas nos estudos críticos mais recentes que confirmam a presença do drama em $O$ amanuense Belmiro. Ampliou-se, contudo, a noção de drama, que não se restringe à oscilação temporal do romance, mas se define também a partir dos conflitos gerados pela figura ambígua do narrador-funcionário público; da relação entre as figuras do autor empírico e do leitor; e do conflito identitário 
do sujeito moderno. Faz-se a ressalva à crítica de Roberto Schwarz que, seguindo o realismo crítico, não identifica a representação estética do drama social no romance.

A crítica marxista de Lukács não explicita as relações entre a burocracia e a produção intelectual, que são amplamente discutidas no artigo de Schwarz. As leituras recentes dos arquivos literários complementam essa leitura crítica já que apresentam uma imagem da figura do escritor inserida na vida cultural e política da cidade moderna. Ampliam-se, assim, as possibilidades de projeção do espaço autobiográfico, que abarca a construção do imaginário dos leitores, configurado a partir da relação entre a obra e os objetos biográficos que compõem o acervo do autor empírico.

A leitura e a perspectiva ideológica de Schwarz é um efeito do período cultural e político referente ao governo militar na década de 1960, que explica a ironia do crítico: "O país de Belmiro, embora silencioso e filosófico, também é cheio de marechais". Da mesma forma, o artigo de Rubem Braga apresenta, implicitamente, uma crítica ao contexto cultural e político da ditadura estadonovista. Distanciados desses contextos históricos, a observação da presença do drama no romance referente aos ensaios de Santiago e Souza resultam da abertura dos arquivos dos escritores modernos. O personagem Belmiro já destinava suas memórias ao leitor do seu "diário", um "leitor futuro" que, no caso da recepção crítica, ressignifica a figura do narrador a partir de novas concepções de história que se utilizam do estudo de textos e objetos biográficos. 


\section{Referências Bibliográficas}

ANDRADE, Mário de. "Psicologia em análise”. O Estado de São Paulo, São Paulo, p. 3, 29 nov. 1939.

ANJOS, Cyro dos. "Abdias, o novo romance de Ciro dos Anjos". Folha de Minas, Belo Horizonte, 16 abr. 1944. Entrevista concedida a Otto Lara Resende, p. 3.

“Cyro dos Anjos”. In: RICCIARDI, Giovanni. Auto-retratos. São Paulo: Martins Fontes, 1991, p. 13-27. Entrevista concedida a Giovanni Ricciardi.

“Cyro dos Anjos”. In: STEEN, Edla Van. Viver \& escrever. Porto Alegre: L\&PM, 1982, p. 13-27.

Entrevista concedida a Edla Van Steen.

. O amanuense Belmiro. Belo Horizonte: Os Amigos do Livro, 1937. Edição fac-similada (UFMG, 2006).

BOMENY, Helena. Guardiães da razão: modernistas mineiros. Rio de Janeiro: Editora UFRJ / Tempo Brasileiro, 1994.

BRAGA, Rubem. "O amanuense Belmiro”. Folha da Manhã, São Paulo, p. 4, 1938.

CANDIDO, Antonio. "Estratégia”. In: . Brigada ligeira. São Paulo: Martins, [1945], pp. 83-90.

FRIEIRO, Eduardo. "O elogio da obra bem escrita”. Folha de Minas, Belo Horizonte, 29 set. 1938. Boletim Literário, p. 3.

LEJEUNE, Philippe. Le pacte autobiographique. Paris: Éditions du Seuil, 1975.

LUKÁCS, Georg. Realismo crítico hoje. Brasília: Coordenada-Editora de Brasília, [1969]. p. 33-75.

MELO, Wander Melo. Corpos escritos: Graciliano Ramos e Silviano Santiago. São Paulo: Edusp; Belo Horizonte: UFMG, 1992.

SANTIAGO, Silviano. A vida como literatura: O amanuense Belmiro. Belo Horizonte: UFMG, 2006.

“O intelectual modernista revisitado". In: Nas malhas da letra. São Paulo: Companhia das Letras, 1989.

. "Suas cartas, nossas cartas". In:

(Org.). Carlos \& Mário: correspondência de Carlos Drummond de Andrade e Mário de Andrade. Rio de Janeiro: Bem-te-vi, 2002.

SCHWARZ, Roberto. "Sobre o amanuense Belmiro". Revista Civilização Brasileira, n. 8, p. 161-170, jul. 1966.

Um mestre na periferia do capitalismo: Machado de Assis. São Paulo: Ed. 34, 2000.

SOUZA, Eneida Maria de. Modernidades Alternativas na América Latina. Belo Horizonte: UFMG, 2009.

Artigo recebido em: 29/01/2010

Artigo aprovado em: 20/02/2010

Referência eletrônica: ALMEIDA, Ananda Nehmy. O leitor de diários e a recepção crítica de $O$ Amanuense Belmiro, Revista Criação \& Crítica, n. 4, p. 52-68, 2010. Disponível em:

<http://www.fflch.usp.br/dlm/criacaoecritica/dmdocuments/05CC_N4_AAlmeida.pdf> 